\title{
Charlas y Conferencias
}

1.- En el mes de abril la: UNPHU celebró a través de su Instituto de Estudios Biomédicos una conferencia-taller titulada " $\mathrm{La}$ Automatización de la Química en los Laboratorios clínicos", en coordinación con la firma norteamericana. Technicon Instruments Corporation CaribbeanTechnicenter, institución especializada en la fabricación de equipos para laboratorios clínicos.

2.- El 18 de abril, patrocinado por la Extensión UNPHU de Santiago, en la Sociedad Amantes de la Luz, del Dr. José de Jesús Jiménez Olavarrieta dictó la conferencia titulada: "La historia de las Grandes Ligas en transparencias seriadas", primera parte para los interesados en la Historia del Beisbol.

3.- Ciclo de conferencias. Las conferencias se celebraron por cuenta del Departamento de Física (Facultad de Ciencias) a cargo del profesor Fabio Valenzuela. La primera, bajo título de "Efectos biológicos de las radiaciones ionizantes", el 23 de abril; la segunda: "Control de Calidad de los equipos de“Teleterapia oncológica", el 29 de abril.

4.- Una serie de conferencias por cuenta de la UNPHU y Altos de Chavón se dedicaron acerca del "Artista dominicano y su identidad". La primera estuvo a cargo del profesor puertorriqueño Ernesto J. Ruiz de la Mata, Director del Centro de Documentación de Arte Latinoamericano Contemporáneo (CEDAL) de San Juan de Puerto Rico, el 17 de abril en la Escuela de Arquitectura de la UNPHU con el tema: "Identidad del Arte de Nuestra América". La segunda conferencia el 18 de abril, en la Escuela de Diseño de Altos de Chavón bajo el mismo tema; $y$ el día 19 un "Coloquio" con artistas y críticos de arte en Altos de Chavón.

5.- También en el mes de abril, bajo los auspicios de la Escuela de Economía, el Licenciado José Luis de Ramón, profesor de dicha Escuela con post grado en Administración de negocios y cursos de Diseño de estrategias de negocios y programas agro industriales en las universidades de Caracas y Cornell dictó una conferencia con el tema: "La administración financiera efectiva contra la inflacción."

6.- El 21 de abril se celebró en el Salón. de Conferencias del Campus 11 de la UNPHU, un simposio sobre: "Arbitraje Civil y Comercial". Participaron en el mismo ex jueces de la Suprema Corte de Justicia y conocidos juristas, entre ellos: Nestor Contín Aybar y 
Luis Victor García de Peña, ex presidente y juez, respectivamente, del alto tribunal.

También expusieron: Marcio Mejía Ricart, Manuel Ma. Miniño, Juan Puello Herrera, Emidglio Valenzuela, Tomás Franjul, Magaly de la Cruz, Fabio Fiallo Cáceres, Carlos Cornielle, Cristina Nina Santana, Luis Pereira Cornielli, Rosa Campillo Vda. Cruz, Nicolás Fermín Ana Rita Bergés de Farray, José Pérez Gómez y Emilio Conde.

7.- El lunes 29 de abril, en el Salón de Conferencia del Campus II pronunció una hermosa conferencia el Excelentísimo señor Morchai David Palzur, Embajador de Israel en nuestro país, bajo el tema "El Shabat: el gran día del pueblo judio." Hizo la presentación del dis- tinguido conferencista el señor Rector, Dr. Jaime Viñas Román.

8.- 14 de junio. En el Aula II, del Edificio del Liceo (Recinto 1) dictó una conferencia bajo título "Importancia de la Cooperatica como empresa", el Licenciado José Moreno.

9.- El Dr. Francisco López Rodríguez, dictó para la Escuela de Veterinaria un curso teórico práctico sobre "Inseminación artificial y diagnóstico de preñez" para la UNPHU en el Recinto Agropecuario Nigua y para médicos veterinarios del Programa de Inseminaciọn Artificial (P|A) de la Dirección General de Ganaderia y miembros del Proyecto Ganadero D-1 del Instituto Agrario en Azua: Duró una semana. 